Perspective

\title{
A global parasite conservation plan
}

\author{
Colin J. Carlson ${ }^{\mathrm{a}, \mathrm{b}, *, 1}$, Skylar Hopkins ${ }^{\mathrm{c}, 1}$, Kayce C. Bell ${ }^{\mathrm{d}, \mathrm{e}}$, Jorge Doña ${ }^{\mathrm{f}, \mathrm{q}}$, Stephanie S. Godfrey ${ }^{\mathrm{g}}$, \\ Mackenzie L. Kwak ${ }^{\mathrm{h}}$, Kevin D. Lafferty ${ }^{\mathrm{i}}$, Melinda L. Moir ${ }^{\mathrm{j}, \mathrm{k}}$, Kelly A. Speer ${ }^{\mathrm{d}, \mathrm{l}, \mathrm{m}}$, Giovanni Strona ${ }^{\mathrm{n}}$, \\ Mark Torchin ${ }^{\circ}$, Chelsea L. Wood ${ }^{\mathrm{P}}$
}

${ }^{a}$ Department of Biology, Georgetown University, Washington, D.C. 20057, USA

${ }^{\mathrm{b}}$ Center for Global Health Science and Security, Georgetown University, Washington, D.C. 20057, USA

${ }^{\mathrm{c}}$ Virginia Tech, Blacksburg, VA 24060, USA

${ }^{\mathrm{d}}$ Department of Invertebrate Zoology, National Museum of Natural History, Smithsonian Institution, Washington, D.C. 20560, USA

e Natural History Museum of Los Angeles County, Los Angeles, CA 90007, USA

${ }^{\mathrm{f}}$ Illinois Natural History Survey, Prairie Research Institute, University of Illinois at Urbana-Champaign, 1816 S. Oak St., Champaign, Illinois 61820, USA

${ }^{\mathrm{g}}$ Department of Zoology, University of Otago, Dunedin, New Zealand

${ }^{\mathrm{h}}$ Department of Biological Science, National University of Singapore, Republic of Singapore

${ }^{1}$ U.S. Geological Survey, Western Ecological Research Center, c/o Marine Science Institute, University of California, Santa Barbara, CA 93106, USA

${ }^{\mathrm{j}}$ Western Australia Department of Primary Industries and Regional Development, South Perth, WA 6151, Australia

${ }^{\mathrm{k}}$ The University of Western Australia, Crawley, Western Australia 6009, Australia

${ }^{1}$ Richard Gilder Graduate School, American Museum of Natural History, New York 10024, USA

${ }^{\mathrm{m}}$ Center for Conservation Genomics, Smithsonian Conservation Biology Institute, National Zoological Park, Washington, D.C. 20008, USA

${ }^{\mathrm{n}}$ University of Helsinki, Research Centre for Ecological Change, Helsinki, Finland

${ }^{\circ}$ Smithsonian Tropical Research Institute, Panama

${ }^{\mathrm{P}}$ School of Aquatic and Fishery Sciences, University of Washington, WA 98195, USA

${ }^{\mathrm{q}}$ Departamento de Biología Animal, Universidad de Granada, Granada, 18001, Spain

\section{A R T I C L E I N F O}

\section{Keywords:}

Biodiversity inventory

Coextinction

Conservation prioritization

Natural history collections

Red listing

Symbionts

\begin{abstract}
A B S T R A C T
Found throughout the tree of life and in every ecosystem, parasites are some of the most diverse, ecologically important animals on Earth-but in almost all cases, the least protected by wildlife or ecosystem conservation efforts. For decades, ecologists have been calling for research to understand parasites' important ecological role, and increasingly, to protect as many species from extinction as possible. However, most conservationists still work within priority systems for funding and effort that exclude or ignore parasites, or treat parasites as an obstacle to be overcome. Our working group identified 12 goals for the next decade that could advance parasite biodiversity conservation through an ambitious mix of research, advocacy, and management.
\end{abstract}

\section{Executive summary}

Metazoan parasites are among the most diverse, threatened, and under-protected animals on Earth, making it increasingly important to ask how and when we should prevent parasite extinctions. However, parasite conservation remains mostly based in theory, without clear goals and priorities, and with few practical guidelines. In this document, a working group of parasitologists and ecologists propose a formal action plan for conserving parasites that do not threaten human health or domesticated species, which the conservation community can leverage over the upcoming decade (2020 to 2030) to minimize the loss of parasite biodiversity. The twelve proposed goals highlight some of the biggest challenges and opportunities for parasite conservation, in four major domains: data collection and synthesis, risk assessment and prioritization, conservation practice, and outreach and education. Achieving these goals will improve future persistence of the ecologically important parasite fauna found across the globe. We found that...

...major scientific questions still need to be answered about parasite biodiversity. Thousands or millions of parasitic animals could be negatively impacted by global change, on scales ranging from local declines to global extinction, and these losses could have major downstream consequences for ecosystem function and stability. However, we cannot fully quantify or address these problems given existing data gaps. Most parasite species in most major parasite groups are still undiscovered or

\footnotetext{
* Corresponding author at: Center for Global Health Science and Security, Georgetown University, Washington, D.C. 20057, USA.

E-mail addresses: cjc322@georgetown.edu (C.J. Carlson), skylar.hopkins@vt.edu (S. Hopkins).

${ }^{1}$ These authors share lead author status. All other authors contributed equally and appear in alphabetical order.
} 
unnamed, and very few species have well-documented distributions or population sizes. These data gaps can be resolved by targeting parasites in biodiversity monitoring and sampling programs; protecting, modernizing, and using biological collections as a resource for studying longterm change; and harnessing modern revolutions in bioinformatics and genomics to track shifting host-parasite interactions and catalog new species.

...parasite conservation is ready to make the jump from premise to practice. Case studies of successful parasite conservation exist, especially where parasites were conserved along with their hosts during host translocation and ex situ host conservation efforts. Following these examples, standard conservation protocols can minimize (real or perceived) tradeoffs between parasite and host vulnerability, and make protecting parasites alongside their hosts the default option. More broadly, frameworks are in place to start protecting parasites in their own right, including vulnerability assessment, classification on Red Lists, and protection through endangered species legislation.

...growing interest in parasite conservation is an asset worth fostering. As academics, conservation practitioners, and stakeholders increasingly work towards advancing parasite conservation, their efforts can be supported through resources and training. At the same time, sharing the benefits and beauty of parasites with the general public through education, outreach, and citizen science could build stronger local and global communities that support parasite conservation efforts.

\section{Introduction}

Conservation biology has a major blind spot. Parasitic species are probably the most diverse and abundant form of metazoan life, but also the most threatened and under-protected (Lafferty and Kuris, 2002; Larsen et al., 2017; Poulin and Morand, 2000; Windsor, 1998). Metazoan parasites represent 15 phyla within the animal kingdom alone (Weinstein and Kuris, 2016), and are famous for having many evolutionary innovations, from behavioral manipulation to host sterilization. Though some parasites represent threats to human health or wildlife conservation, the majority of species have no zoonotic potential (see Box 1). Moreover, though parasites cause some harm to individual hosts, their net impacts at higher orders of ecological organization are more complex, suggesting that parasite conservation paradigms should align with the 20th century paradigm shift around predator conservation (Dougherty et al., 2016). In particular, many parasites play critical roles in ecosystems by contributing to biomass flow, food web connectivity, and population control, and by driving the evolution of other species (Dunne et al., 2013; Hudson et al., 2006; Kuris et al., 2008; Lafferty et al., 2008; Sato et al., 2011). Unlike most other taxa, parasites face a double threat: they are directly vulnerable to extinction due to anthropogenic factors like climate change or invasive species (Carlson et al., 2017a), and indirectly vulnerable through coextinction with hosts (Lafferty, 2012), especially in changing environments (Strona and Lafferty, 2016). By some projections, this might make parasitic groups among the most threatened taxa on Earth, and consequently-given their hyperdiversity_it might mean that parasites account for the majority of species facing extinction (Carlson et al., 2017a).

Such concerns have led to decades of sporadic calls for efforts to conserve non-zoonotic parasite species (Dougherty et al., 2016; Durden and Keirans, 1996; Gómez and Nichols, 2013; Pizzi, 2009; Whiteman and Parker, 2005; Windsor, 1995). However, these review and opinion pieces, and their underlying risk assessments, have yet to be translated into conservation practice. Only a handful of parasite species have a formal International Union for Conservation of Nature (IUCN) Red List entry, and few are protected by threatened species legislation (Dougherty et al., 2016). Some species may be incidentally protected by measures like protected areas that are intended to conserve their hosts, but other host conservation efforts may harm parasites (e.g., disinfection practices during captive breeding or translocation). Most parasitic groups lack clear guidelines for how conservation practices, from risk assessments to ex situ breeding, should adapt to the unique aspects of their life cycles. These challenges are confounded by the data deficiency that exists for most parasite groups relative to free-living animals or plants. If parasites are a major component of the sixth mass extinction, almost no deliberate mechanisms are in place to prevent their catastrophic decline.

Here, we describe a global action plan that we believe would take parasite conservation from a horizon-scanning exercise to mainstream conservation over the next decade (2020-2030). This paper, and the special issue of Biological Conservation that it was prepared for, are the product of a workshop held at the 2018 Ecological Society of America Conference, in New Orleans, Louisiana. The goal of this working group was to combine expertise that includes parasitology, systematics, ecology, evolutionary biology, genomics, museum science, conservation, and modeling, and to produce a coherent but ambitious plan for how to combat the expected parasite extinction crisis. This project represents the combined expertise of authors with affiliations in six

Box 1

Formal scope-setting: Which parasites need conservation?

Discussion of parasite conservation is often met with concerns about scope and potential repercussions. Do all parasites deserve protection? What about Guinea worm? Viruses and bacteria may face coextinction risk (Dunn et al., 2009); do they deserve protection?

This document provides a set of guidelines for the protection of metazoan macroparasites of animals that have been proactively identified as safe and low-risk targets for conservation. Here, we define "parasites" as species whose trophic strategy depends upon living on, or in, one or a few hosts and extracting host resources at some stage in their lifecycle. Consuming host resources should cause some form of harm to individual hosts, but "parasitic clades" may include species that are not measurably detrimental to hosts; in fact, re-examining symbiont biology can occasionally turn up cases where commensalistic or mutualistic species have been miscategorized (Doña et al., 2019; Jovani et al., 2017). To account for this, our conservation plan applies to all metazoan species within parasitic clades, ruling out pathogens or microparasites, like viruses and bacteria, as well as parasitic plants, which already receive substantial conservation attention (Marvier and Smith, 1997). Following the simple triage system in Dougherty et al. (2016), which was built on the precautionary principle, we deliberately exclude:

1. Parasites that are a known or suspected risk to human health, wellness, or livelihoods (e.g. through fisheries or domestic animals). For example, in the Natural History Museum's Host-Parasite Database (www.nhm.ac.uk), 688 species of parasitic worms are recorded as zoonotic out of a total 19,951 (about 4\% of species; Dallas, 2016; Gibson et al., 2005), and we do not advocate for their conservation. Even more metazoan parasite species have an untold burden on the health, wellness, economies, and development of human populations, especially across several countries in the Global South. Our conservation goals do not apply to these parasites, and we admire the efforts of the broad global coalitions that have spent decades working towards the eradication and eventual extinction of parasites like Guinea worm and lymphatic filariasis.

2. Parasites that threaten their host's conservation, unless alternate hosts or methods of ex situ preservation can be devised. In cases where parasites are necessarily sacrificed to protect hosts (e.g., eradicating sarcoptic mange mites to conserve carnivores; Pedersen et al., 2007), with no alternative, it would instead be fitting to preserve them in collections and to do our best to describe their autoecology and extinction in permanent data sources like the IUCN Red List. 
countries and research projects in several more, but in many cases, we have defaulted to focusing on American, European, or Australian examples. In doing so, we both acknowledge that parasite conservation may be more defensible or feasible in countries with more funding available for experimental conservation programs, and have deliberately aimed to avoid making recommendations about organizations, societies, regions, or communities beyond our personal and academic experiences. In the long run, our goal is to develop an infrastructure and coalition that can be broadened to be more globally inclusive.

Our proposed plan has twelve goals (Fig. 1), organized around four themes:

1. Data collection \& synthesis: In the coming decade, which data are needed to inform parasite conservation? How should they be collected, stored, and analyzed? How does that research need to be supported? (Goals 1, 2, 3, and 12).

2. Risk assessment \& prioritization: Which parasites are threatened? How is parasite vulnerability different from, and exacerbated by, host vulnerability? How do we formalize that knowledge? Who should perform the assessments? (Goals 4, 5, and 6).

3. Conservation practice: What actions in the field, laboratory, and ex situ conservation setting are needed to prevent parasite extinctions and to preserve parasites into the future? (Goals 7 and 8).

4. Outreach \& education: What needs to happen to move parasite conservation into mainstream fields within and outside of academia?
How might the public support parasite conservation? Can we leverage parasite conservation efforts to get people interested in and enthusiastic about parasites? (Goals 9, 10, and 11).

We conclude with a discussion of challenges, and potential future directions for research.

\section{Theme 1: data collection \& synthesis}

Goal 1. Add parasite biodiversity to survey efforts for free-living species

Species inventories and checklists rarely include parasites, leaving parasites both out of sight and out of mind for the scientists who survey and monitor biodiversity. Systematically collecting parasite data during free-living biodiversity surveys would help to establish current parasite biodiversity baselines, identify rare parasite species, and monitor future changes in parasite biodiversity (Gehman et al., 2019), a resource-efficient and effective way to advance parasite biodiversity conservation in spite of the (current) lack of dedicated funding. Below we note some specific opportunities and challenges for these new endeavors.

In both personnel and funding, field biologists who study free-living organisms greatly outnumber parasitologists. Therefore, building parasites into field surveys will ultimately depend on the participation and technical capacity of the broader scientific community. However, most investigators will lack the expertise or training to collect parasites

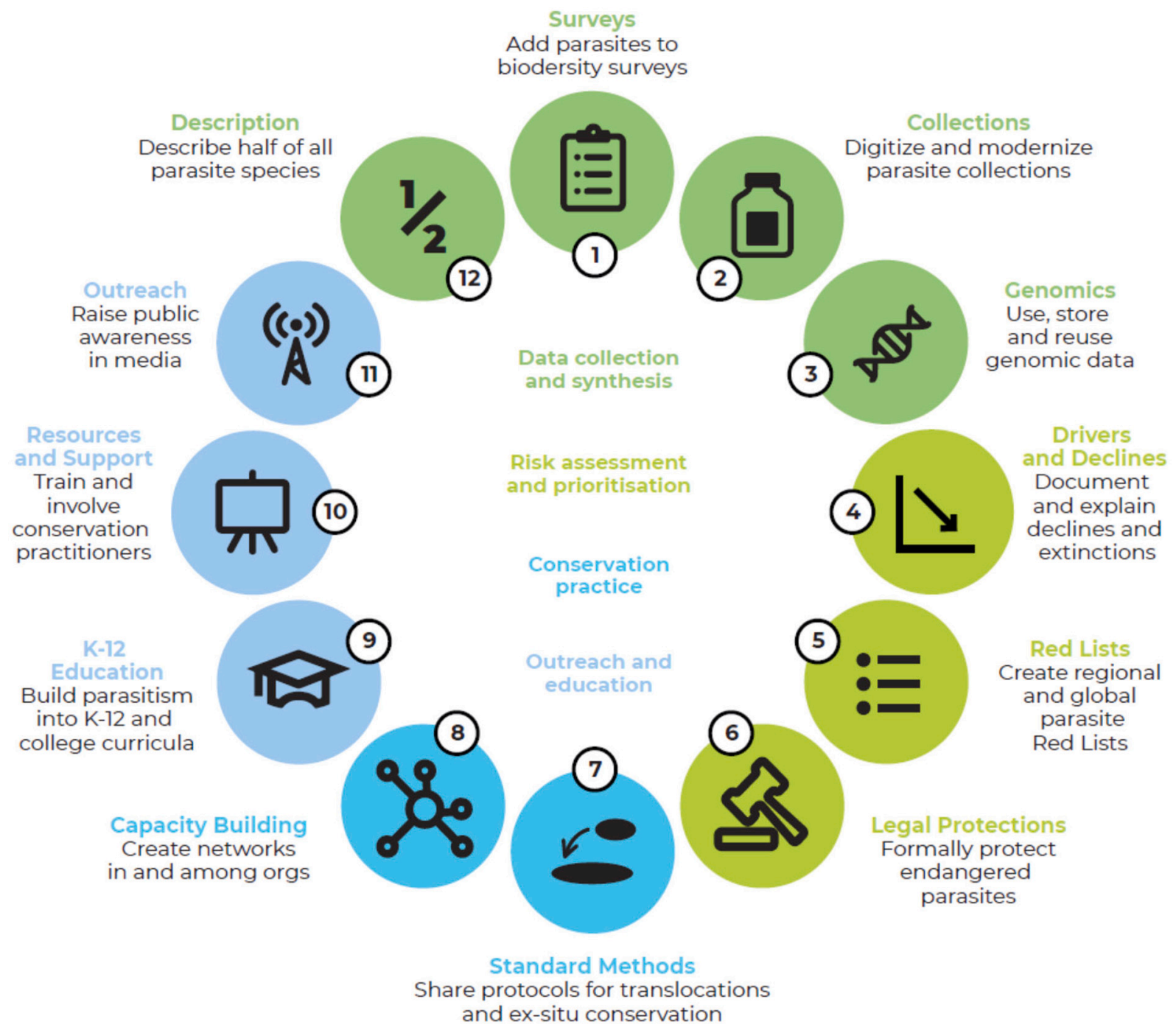

Fig. 1. The twelve major goals in the parasite conservation plan. 
without the support of a parasitologist. By working together, field parasitologists, zoologists, and curators could create and distribute protocols for collecting free-living species in ways that maximize collection and preservation of associated parasite data (also see Goal 10). An exemplary document was recently produced for mammalogists, which describes the technical aspects of parasite collection in field studies for people with little to no parasite expertise (Galbreath et al., 2019). Similar documents are needed for all major vertebrate groups, especially amphibians and reptiles, which may have some of the most co-threatened parasites, but are severely under-represented in collections.

Another key priority will be to survey rare and threatened host species for parasites. These parasites might face the highest coextinction risk and might be the most poorly described and poorly studied symbiont fauna, given host rarity. Veterinarians often investigate host health, but rarely consider coextinction, so routine health examinations could be expanded to include parasite taxa not considered to threaten host health and to deposit samples in museum collections. Parasite data from these rare host species could be acquired when hosts are handled or permanently collected, or their blood, tissues, or feces are sampled. In many cases, this would not require additional permits beyond those already required for collecting free-living hosts. Furthermore, for animals that are being sacrificed and for rare animals (e.g., anesthetized wild cats that are being radio-collared), collecting parasite data would help to meet the ethical mandate to maximize scientific value stemming from each disturbance. Therefore, animal ethics and welfare committees and permitting agencies for wildlife trapping and collection can request that investigators working with rare and endangered species explain how their samples will be permanently preserved. For specimens of particular importance, permit-grantors could recommend that samples be archived in museum collections (also see Goal 2), rather than laboratory freezers and cabinets, where they are inaccessible to the research community and may never be used again.

Although we prioritize understanding the parasites of rare and endangered hosts, it is equally important to systematically survey general parasite biodiversity by adding parasite biodiversity surveys to largescale biodiversity monitoring programs (also see Goal 12). These programs include the Long Term Ecological Research Networks in the United States (LTER; lternet.edu) and Australia (LTERN; www.ltern. org.au), and the National Ecological Observatory Network (NEON; www.neonscience.org) and Marine Global Earth Observatory (MarineGEO; marinegeo.si.edu) in the United States, as well as more bottom-up surveys like BioBlitzes and citizen science efforts like iNaturalist $^{\mathrm{TM}}$ ( $w w w$.inaturalist.org). Given the diversity of parasites, their inclusion in these programs poses a triage problem, with no definitive solution; previous efforts to include parasites in NEON protocols were met with criticism for focusing on zoonotic taxa, a purview too narrow to set an informative ecological baseline (Cook et al., 2016; Springer et al., 2016). Instead, most parasitologists have agreed that including a few parasite taxa that are relatively easy to collect, identify, and preserve (e.g., trematodes, ectoparasitic arthropods, leeches) would greatly increase knowledge regarding parasite biodiversity (Cook et al., 2016; Galbreath et al., 2019). These new efforts would require that programs seek out more collaborations with parasitologists, just as they currently collaborate with ornithologists, herpetologists, and other biological specialists (also see Goal 10).

To promote these changes, funding agencies (e.g., U.S. National Science Foundation, U.S. Department of Agriculture, Australian Research Council, Taiwan's Academia Sinica, European Commission) and grant reviewers for biodiversity projects can require statements on how parasite biodiversity will be included in projects, or, if excluded, a justification for parasite biodiversity exclusion. In the United States alone, successful adoption of this recommendation would yield parasite species checklists for every Level I ecoregion within the next 5-10 years. Globally, these endeavors will greatly increase known parasite biodiversity (see Step 12) and provide information to support informed decision-making by managers committed to parasite conservation.

\section{Goal 2. Digitize and modernize the major parasite collections}

Biological collections are a fundamental resource in parasitology, and their role will become more critical in a changing world. For researchers interested in studying parasite responses to global change, collections are the most extensive and complete source of data on the past and present diversity, distribution, and abundance of parasites, as well as genomic information and known host ranges (Bell et al., 2018; Carlson et al., 2017a; Dallas et al., 2018; DiEuliis et al., 2016). As such, they are some of the only permanent records of ecological "baselines" and long-term change in parasite biodiversity, and are increasingly used to reconstruct range shifts, colonization-extinction dynamics, and even host shifts (Harmon et al., 2019; Tingley and Beissinger, 2009). In some cases, collections could be the only record of parasites driven to extinction by anthropogenic change, as they are for many free-living species (Cotterill, 1997; Mares, 2009).

However, collections are only permanent as long as they are maintained, and are only as valuable as they are accessible. Nearly a hundred parasite collections with 3.7 million lots are housed at museums, academic centers, and other research institutions around the world. However, many collections are undigitized, and therefore their specimens are inaccessible for most research purposes (Bell et al., 2018); only a third of collections have a public data portal, and interfaces like Global Biodiversity Information Facility (GBIF; gbif.org) and Arctos (arctos.database.museum) only cover some institutions. Moreover, many collections face a combination of institutional defunding and neglect that can jeopardize the continued existence of irreplaceable specimens, and sometimes lead to their destruction or abandonment (Escobar, 2018; Mares, 2009). When catastrophe strikes undigitized collections, most data will be impossible to recover. These barriers make it harder to know how many (and which) parasites need conservation protections.

By the end of the decade, a proposed goal includes developing public interfaces to $90 \%$ of known parasite collections worldwide, and to have digitized half of all lots. Historically, success has been achieved by dedicated working groups with collections expertise that can travel to perform rapid digitization work, such as the Planetary Biodiversity Inventory tapeworm project (Caira and Jensen, 2017). This can be facilitated by developing and publishing standardized protocols for georeferencing and digitization of parasite collections, and forming a rapid impact group to train collections staff, initiate digitization, and establish a multiinstitution infrastructure for sharing digitized data. Funding and training will be especially effective for smaller collections with limited dedicated staff. Digitizing the largest collections will also set an important precedent, and help test and formalize digitization procedures. For instance, fully digitizing and georeferencing the public-facing U.S. National Parasite Collection (one of the largest parasite collections in the world) by 2025 is an achievable next step. The required investment for this goal is relatively small; half the U.S. National Parasite Collection was already georeferenced by volunteers in approximately two years without funding (Carlson et al., 2017a).

\section{Goal 3. Applying conservation genetics and genomics to parasites}

Conservation genetics can be used to identify at-risk species, assess conservation impacts, and restore ecosystems (Assis et al., 2013; Benestan et al., 2016; Breed et al., 2019; Supple and Shapiro, 2018). This suite of tools would be especially useful in assessing the risk status of parasite species, where population size and dispersal is difficult or impossible to assess without molecular genetics (Criscione, 2016; Criscione et al., 2005). Molecular data from contemporary parasites can also be used to reconstruct historical population sizes, and identify the timing of major changes in host ecology, like population bottlenecks (Crellen et al., 2016; Margos et al., 2012; Whiteman and Parker, 2005). However, genetics and genomics have not yet been employed to facilitate parasite conservation, in part due to limited genetic resources and 
difficulty in applying conservation genetics analyses built for free-living species to parasite species. Therefore, researchers, practitioners, professional societies, and funding organizations could increase genome sequencing and DNA barcoding of parasites and further develop conservation genomics tools for parasites.

Although there have been efforts to increase genome sequencing (especially DNA barcoding) of parasites, even the most comprehensive databases are missing information for most parasite species (Morand, 2018). By 2045, the International Barcode of Life (iBOL; ibol.org) aims to have a sequence for every species (Planetary Biodiversity Mission; Hobern, 2019). This goal is especially ambitious for parasitic species when, for example, only $2 \%$ (663 out of 30,000 ) of described Platyhelminthes species (Caira and Littlewood, 2013), 3\% (38 out of 1300) of Acanthocephala species (García-Varela and De León, 2015; Poulin and Morand, 2014), and 9\% (175 out of 1900) of feather mite species (Astigmata: Analgoidea and Pterolichoidea) (Doña et al., 2016) have barcodes published on the Barcode of Life Database.

A reasonable landmark would be to barcode more than $50 \%$ of known species and $90 \%$ of genera of each parasitic clade within the next decade. This goal can be achieved by: (1) rapidly increasing genetic resources for parasites through direct sequencing efforts (i.e., generating genomic data through high-throughput sequencing of parasite samples); (2) leverage available genome data of parasitic species generated for other purposes (e.g., phylogenomics); (3) using whole-genome data from free-living hosts to mine reads belonging to their associated parasites; and (4) developing protocols and plans for extracting genomic data from biological collections (Yeates et al., 2016). Opportunistically mining global sequencing initiatives like the Earth BioGenome project (www.earthbiogenome.org), Bat $1 \mathrm{~K}$ (bat1k.ucd.ie), and 1000 Plant Transcriptomes (1KP; https://sites.google.com/a/ualberta.ca/onekp/) is one way to cost-effectively advance genetic resources for parasites. Beyond these efforts, parasitology journals can call for more genetics and genomics resource papers to further encourage the advancement of genomes and parasite barcoding.

Beyond the need for genetic resources for parasites, we must also consider how conservation genetics tools require tailoring to the idiosyncrasies of parasitism. Due to their complex life cycles - which often include multiple life stages, associations with multiple hosts, rapid generation time, and variable population sizes - standards for assessing the conservation status of free-living species are hard to apply to some parasite species (Doña and Johnson, in this special issue). For example, parameters such as effective population sizes, genetic diversity, population genetic structure, and level of introgression are commonly estimated in conservation genetics research for free-living species (Benestan et al., 2016; Supple and Shapiro, 2018), but may be more complicated-or simply incorrectly calculated-for parasites, due to their natural history and demographic characteristics (Criscione, 2016; Doña and Johnson, in this special issue; Speer et al., 2019; Van Schaik et al., 2015). Therefore, increased availability of genomic material (e.g., reference sequences; Esteban et al., 2018) and adapted methods from well-developed protocols that facilitate molecular work with problematic taxa (e.g., Vizcaíno et al., 2018) are needed to facilitate conservation of parasites. In this vein, conservation- and parasite-focused journals can solicit papers developing these methods and associated societies can look to support these efforts.

\section{Theme 2: risk assessment \& prioritization}

Goal 4. Document parasite declines and extinctions, and identify corresponding drivers

Between 3\% and 33\% of parasites might be threatened with extinction (Carlson et al., 2017a; Dobson et al., 2008), but almost no empirical evidence supports (or contradicts) these projections. Parasite extinctions are chronically under-reported, where most known instances are cases of coextinction or coendangerment during captive breeding and host translocation (Jørgensen, 2015; Rózsa and Vas, 2015), or cases where parasite records were retrospectively exhumed after host declines (e.g., Mac Kenzie and Pert, 2018). These isolated data points are far more sparse than predicted by coextinction theory, a "paradox of missing coextinctions" (Strona et al., 2013). Recent research has begun to explore how climate change and other anthropogenic drivers might directly threaten parasites, separate from host vulnerability (Carlson et al., 2017a), but these projections are also unvalidated; despite important evidence from isolated studies (Bush et al., 2013; Cebolla et al., 2018; Esser et al., 2019; Zhan et al., 2018), no systematic effort has been undertaken to document parasite range loss or prevalence declines. The few long-term datasets that exist are biased towards parasites of zoonotic or economic concern that are increasing (or projected to increase) in abundance or geographic range (Cizauskas et al., 2017; Fiorenza et al., n.d.; Howard et al., 2019). To better understand what drives parasite biodiversity declines, more longterm datasets on parasite abundance, distributions, and diversity would need to be collected, and then used to formally validate existing predictions of parasite biodiversity declines during mass extinctions.

To that end, one important next step is to better document parasite extinction events. Assessing and protecting more endangered parasites will eventually increase the number of recorded extinctions (Goals 5 and 6), but we can also search for previously missed extinction events, and retrospectively reconstruct parasite declines. This can be accomplished for the recent past (i.e., $\sim 150$ years) by parasitological dissection of liquid-preserved specimens (Black, 1983; Hartigan et al., 2010; Howard et al., 2019; Johnson et al., 2003), combing feathers/fur for ectoparasites on preserved skins (Bell et al., 2015; Clayton and Walther, 1997; Hellenthal and Price, 1991; Mey, 2002; Valdez et al., 2009), or extracting parasite DNA from specimens (Ouellet et al., 2005; Talley et al., 2015; Weldon et al., 2004). To go further back in time (centuries to thousands of years), other sources, such as woodrat middens (Cole and Arundel, 2005; Webb and Betancourt, 1990), raptor pellets (Beltrame et al., 2016; Grayson, 2000), ancient DNA preserved in coprolites (Boast et al., 2018), host-symbiont cophylogenies (Doña and Johnson, in this special issue), and even whole parasites in frozen mammoths (Grunin, 1973) can be used to document prior parasite extinctions (Harmon et al., 2019). In some cases, museum data may even be used to statistically test the extinction status of missing parasite fauna (Carlson and Phillips, in this special issue). To better enable these types of studies, parasitologists and curators can establish and publish formal best practice procedures for the use of collections to document historical parasite fauna, with minimal or carefully considered destructive damage to irreplaceable specimens, ideally by experienced researchers in tandem with collection digitization efforts (Goal 2).

To validate models that predict how anthropogenic pressure will disassemble host-parasite networks, researchers will need new longterm datasets that capture the dynamics of entire parasite communities. For example, the Arctic is one rapidly changing ecosystem, and a few Arctic mammal parasites have important human health implications (Kutz et al., 2012). The full community of parasites of Arctic mammals, both zoonotic and benign, may therefore represent a good candidate for a long-term, comprehensive parasite community dataset (Kutz et al., 2009). At a minimum, in the next decade, researchers could generate several long-term $(100+$ years $)$ parasite-community datasets to help validate predictions of parasite extinctions or declines. These datasets need to be as complete as possible in the host-parasite associations documented, because most existing datasets are missing a significant proportion of likely interactions, potentially making them unreliable for this purpose (Carlson et al., 2019a, 2019b; Dallas et al., 2017; Poulin et al., 2016).

Goal 5. Develop and publish regional parasite Red Lists, and expand the parasite coverage of the global IUCN Red List

Red Lists help prioritize conservation action (Cardoso et al., 2012), 
but fewer than a dozen species with adult parasitic stages have been redlisted; most listed "parasites" are groups like mussels and butterflies that have a parasitic or holobiont stage and a free-living adult of conservation concern. A preliminary Red List for parasites was proposed in 2017, but remains unpublished and is no longer maintained or updated (Carlson et al., 2017b). As has been argued for other non-parasitic invertebrates, parasite conservation is unlikely to be practiced effectively, or taken seriously as a funding or research priority, until parasites have a greater presence on the IUCN Red List (Cardoso et al., 2012). Given that parasite species number in the millions, an ambitious goal would be to formally assess $1 \%$ of parasitic diversity (including species listed as Data Deficient or Not Threatened) for the IUCN Red List. Within this special issue of Biological Conservation, two papers describe how to streamline efforts and resources to list parasites (Kwak, in this special issue; Moir and Brennan, in this special issue). Further, developing a co-Red List to protect the parasites of $1 \%(\sim 500$ species $)$ of the animals listed as threatened on the IUCN Red List, focused on the conservation of flagship species for maximum impact and justifiability would strengthen this goal. These goals pose an organizational problem due to the complexity and novelty of parasite conservation, but this challenge would be ameliorated by forming an IUCN Working Group on Parasites (Goal 8), adding to existing IUCN criteria and categories to accommodate parasites more easily (Moir and Brennan, in this special issue), and collecting more detailed parasite abundance and distribution data (Goals 1-4).

\section{Reviewing knowledge}

\section{Have parasites been recorded from this species?}

Yes - then, are they:

- Host specific?

- Rare?

- Known to be pathogenic?

- What is their transmission method/lifecycle?

- Are they native or introduced?
No - then:

- Is a survey possible?

- Are there related species that could offer some insights?

- Are there any likely pathogens to be concerned about?

\section{Consider further research to improve knowledge}

\section{Conservation prioritisation}

- Assign higher priority to parasites that are host-specific/rare

- Identify parasites that are of concern due to the disease risk they pose

\section{Translocation planning}

\section{Parasite attribute}

Helminth or arthropods (targets organisms with chitin)

Lifecycle involves intermediate host, alternative hosts or vector

Transmission method requires close proximity/contact

Pathogenic potential

\section{Action}

Avoid use of ivermectin as a part of translocation protocol

Survey site to determine if intermediate hosts/vectors are present - if not, translocate them as well

Use soft-release protocol to increase host density during early stage of translocation.

Identify appropriate methods to control (either eliminate or reduce load) of target parasite.

\section{Add/select further actions as appropriate}

\section{Cost-benefit analysis}

Identify costs and benefits of conflicts that arise during conservation action phase to determine best course of action. Where cost/benefits are unknown:

$\rightarrow$ Consider employing an experimental approach (where appropriate) to improve our understanding of the outcomes of given management approaches.

$\rightarrow$ Otherwise, apply the precautionary principle (although this will likely result in parasite elimination).

\section{On-going management}

- Include parasite monitoring as a part of translocation protocols

- Identify appropriate intervention criteria and actions

- Publish results of follow-up monitoring and translocation outcomes, and use information to inform future management actions

Fig. 2. An outline of how parasite conservation can be considered in translocation planning. 
To advance progress towards this goal, developing regional or placespecific Red Lists across the planet is suggested. Systematically assessing the vulnerability of the entire parasite fauna of the most threatened hosts in a community is a strategy that can optimize resources, help identify parasite extinction risk at a finer scale than host risk, and support efforts to co-list threatened interactions (Cardoso et al., 2012; Moir and Brennan, in this special issue; Thompson et al., 2018). Expanding the purview of these efforts to include all metazoan symbionts will help connect parasite conservation with other invertebrate Red Listing efforts, and help capture groups in which the nature of the hostsymbiont relationship is less certain (Box 1). In some cases, thorough inventories may also lead to the description of new parasite species or re-description of poorly characterized taxa (Kwak et al., 2018; Kwak, 2018; Kwak and Heath, 2018), supporting efforts to describe global parasite diversity (see Goal 12).

In biodiversity hotspots and places of major ecological turnover, host-level total assessments can be aggregated to form the basis of new regional parasite Red Lists. A regional focus is likely to be strategic: Red Listing of parasites has been more commonly attempted at national or regional scales than globally, with many more species already listed for better-recognized groups like the leeches (Carlson and Phillips, in this special issue). Therefore, regional parasite Red Lists for at least all five vertebrate groups could be developed for critical ecosystems, including the Amazon (a notoriously undersampled biodiversity hotspot for parasites) and the Arctic (a hotspot of rapid ecological change, including in host-parasite associations), by 2030.

Goal 6. Protect select parasite species under formal state, federal, or international threatened species legislation like the ESA

Threatened species legislation has a powerful role in every aspect of conservation, from the protection of critical habitats to the allocation of research funds. Invertebrates are increasingly included in these assessments, but parasites remain severely under-represented. Leeches are perhaps the best-protected obligate parasites, with Hirudo medicinalis and $H$. verbena regulated under the Convention on International Trade in Endangered Species of Wild Fauna and Flora (CITES; www. cites.org) and federally listed in several European countries; and in the United States, the presumed-extinct leech Macrobdella sestertia is listed as threatened in Massachusetts and as a species of special concern in South Carolina (Carlson and Phillips, in this special issue). In the United States, several species of freshwater mussels (which spend a life stage as parasites on fish gills) are listed as threatened or endangered on the Endangered Species Act (USFWS, 2019), and these are the only parasitic species listed federally. Beyond these examples, effectively all threatened parasites are unlisted globally.

Advancing state and federal listings of threatened parasites would formalize knowledge about parasite vulnerability, support protection of critical habitats, add value to conservation efforts previously focused on single species (the host), and disincentivize host conservation measures that unnecessarily lead to parasite eradication (see also Goal 7). The last of these is especially important, given the history of coextinctions resulting from the protection of charismatic species like the blackfooted ferret (Mustela nigripes) or the California condor (Gymnogyps californianus), which have otherwise been framed as success stories for conservation (Dougherty et al., 2016; Gompper and Williams, 1998; Jørgensen, 2015; Rózsa and Vas, 2015). One major goal, therefore, could be the assessment and co-listing of threatened parasites for all the regions in the world that have high proportions of extinct or threatened mammals and birds; for a systematic approach, regions with extinction levels of above $5 \%$ of the total fauna, or threatened levels above $10 \%$. For example, New Zealand has the world's highest rate of bird extinctions, with 59 species or subspecies extinct (12\%) and another 70 threatened (14\%), from the total fauna of 487 species or subspecies (Robertson et al., 2017). For mammals, Australia has one of the worst records, where $7.5 \%$ of 357 native species have gone extinct (27 species) and a further $30 \%$ are threatened (107 species) (Australian Department of the Environment and Energy, 2019). There is a need for prioritizing efforts to assess and co-list parasites of these vertebrate taxa in these and other extinction hotspots.

\section{Theme 3: conservation practice}

Goal 7. Standardize protocols for including parasites in faunal translocations and ex-situ faunal conservation, including cost-benefit justifications

Host translocation and conservation efforts may directly (e.g., delousing; Gompper and Williams, 1998) and indirectly (e.g., through the loss of intermediate hosts or vectors; Fairfield et al., 2016) threaten the survival of parasite species, so explicit actions to conserve parasites alongside hosts should be considered as a part of conservation planning. This contrasts past efforts, which have focused on the disease risk that parasites pose during translocations. Most protocols were designed to minimize the transfer of parasites with their threatened hosts (e.g., Corn and Nettles, 2001; Ewen et al., 2012), due to concerns that parasites may be detrimental to the establishment of viable host populations (Cunningham, 1996; Kock et al., 2010). However, growing evidence suggests that not all parasites are detrimental during host conservation activities (Northover et al., 2017), and exposure to parasites may even convey benefits to translocated individuals and populations (Van Oosterhout et al., 2007). Indeed, some putative parasites may have been wrongly categorized as parasites, and can be revealed as mutualists or commensals after careful study (Doña et al., 2019). Therefore, we suggest several steps that can be taken to conserve relatively benign parasites during host translocation efforts.

Standardized protocols can be developed for considering whether and how parasites should be conserved during fauna translocations (Fig. 2) and other conservation activities. Although some work towards this has begun (e.g., Moir et al., 2012; Plein et al., 2016), there is much yet to be examined and defined to create holistic, standardized protocols. In particular, such protocols could consider the effects of parasites on the host species, the different transmission strategies and life cycles employed by parasites, and how those details impact parasite conservation actions. Assessments could also include the minimum viable host population size required and how this changes depending on parasite or host (Dougherty et al., 2016; Moir et al., 2012), the timing of parasite translocations (Plein et al., 2016), and the influence of augmenting host populations on parasite dynamics (Northover et al., 2019). Post-translocation monitoring plans that allow some assessment of the effectiveness of the management approach for both hosts and parasites are also needed. These protocols can balance parasite conservation with the success of translocations and management for the host species, and planning may require comparing the costs to benefits for particular management protocols for each species. Even if this process reveals that parasites are too detrimental to the host or that parasite conservation efforts would be too costly or unfeasible, the management of all species would be transparent, and any collateral loss of secondary species can be documented and acknowledged.

While the IUCN considers parasites and diseases as a part of their guidelines on conservation translocations (IUCN/SSC, 2013), parasite conservation is currently only considered in the context of reintroduction of an extinct host whose parasites may have also become extinct. Since the IUCN guidelines on conservation translocations are the "gold standard" for translocation protocols and permitting, the inclusion of clear parasite conservation protocols as a part of IUCN guidelines would enhance parasite conservation management during translocation planning. Similarly, each authorizing body that permits translocations has different standards and advice regarding the consideration of parasites and disease. Encouraging the adoption of these protocols as a part of the permitting processes for authorizing bodies could help to determine whether and how parasites may be conserved as a part of conservation management 
activities. Although this goal is non-trivial, many of the considerations we highlight can be conducted simultaneously with disease risk evaluation (Fig. 2). Existing conservation management programs also merit review to evaluate their implications for parasite conservation. For instance, the health management of the Tasmanian devil (Sarcophilus harrisii) insurance population consisted of the routine use of anthelmintics, but this practice has now been discontinued in an effort to conserve the devils' parasitic fauna (Wait et al., 2017). By keeping the process relatively simple, and minimizing the burden added to existing processes, parasite conservation may effectively be taken into account during conservation planning.

Goal 8. Build parasite conservation capacity by creating new organizations and new affiliations among existing organizations

There has already been substantial effort to build conservation capacity for some charismatic and economically important parasite taxa. For instance, lycaenid butterflies and freshwater mussels fall under the purview of existing IUCN Specialists Groups for butterflies and molluscs, respectively, and thus many species in each group have been formally assessed by the IUCN (Ferreira-Rodríguez et al., 2019; IUCN, 2017; New, 1993). Global assessment for these species has helped to incite national and regional working groups and assessments, which in turn sparked enough capacity building that species in each group have benefitted from national protections, captive breeding or reintroduction efforts, designated protected areas, monitoring programs, and other conservation actions. We could scale up from these examples for specific parasite taxa to conserve parasite biodiversity more broadly, starting with the first global and regional network-building actions that will trigger future investment and action.

A principal capacity building action for parasite conservation would be forming at least one Parasite Specialist Group within the IUCN Invertebrate Conservation Sub-Committee. A single Parasite Special Group would cover more species and taxonomic breadth than any of the existing 17 invertebrate specialist groups (e.g., butterflies, corals, cave invertebrates), and thus would require a larger and broader membership with regards to taxonomic expertise. However, a single group is likely preferable to establishing many taxon-specific specialist groups (e.g., Tick Specialist Group, Flea Specialist Group), because one group will require less activation energy and can work through new, parasitespecific assessment details systematically and consistently across taxa. In fact, the first goal of the Parasite Specialist Group could be to edit a special volume on parasite conservation, as has been done for other groups (e.g., "The Conservation of Lycaenidae butterflies"; New, 1993).

Outside of the IUCN, there can also be global and regional networks of individuals who are interested and trained in parasite conservation. To some extent, these networks can be initially structured through the global and regional networks already interested in parasitology; for instance, the World Federation of Parasitologists is composed of 88 regional, national, and international parasitology societies. But existing parasite societies often focus on parasite biology and control, not conservation, and would benefit from the transfer of knowledge from specialist conservation biologists. Therefore, some capacity building would be needed to build networks and initiatives across professional societies specific to parasites, other invertebrates, and conservation (also see Goal 11). Additionally, a list of parasite conservation researchers and practitioners could be created and made accessible on the Internet, to facilitate the formation of new networks as they become necessary. Such a list could be maintained by a future IUCN Parasite Specialist Group, the World Federation of Parasitologists, or a conservation committee within a national parasitology society (also see Goal 11). These new local and global networks across and within existing organizations that promote top down support will be the drivers of most future parasite conservation actions.

\section{Theme 4: outreach \& education}

Goal 9. Integrate parasitism into public education (and train the next generation of parasitologists)

Parasitism is currently underrepresented in textbooks and courses at all levels, for general and specialized education alike. For instance, conservation textbooks usually portray parasites as threats to free-living species or exclude parasites entirely (Nichols and Gómez, 2011), and ecology textbooks and curricula focus far more on other species interactions, like predation. As a result, even biology professionals know little about parasitism, and there is a shortage of experts who specialize in parasites (Shaw and Hochberg, 2001). Improving curricula regarding parasites would more accurately portray parasite biodiversity to future biology and conservation professionals, inspire the next generation of parasitologists, and improve public understanding of why parasite conservation is important.

The specific parasite-themed content that would be appropriate will depend on the level and course, and thus we make several contextspecific suggestions for learning goals. By the time students reach university, they would know what parasites are, that all animals have at least one parasite, and that parasite species are as diverse, abundant, ecologically important, and threatened as predators. At the undergraduate level, we suggest that biology students know that there are career opportunities related to parasites, and that parasites are considered during free-living host conservation efforts. Veterinary medicine curricula already include parasitology content, but at the undergraduate and graduate levels, these students would know that not all parasites cause substantial harm to their hosts, and that eliminating all parasites from wildlife can actually be detrimental for host conservation (Spencer and Zuk, 2016). In short, all biology courses covering content at the organism level or above could include parasite content, including the positive ecological and societal values associated with parasites (e.g., organic pest control).

To accomplish these learning goals, we can use multiple methods and tools to increase parasite content in school and undergraduate curricula. Within broad, existing undergraduate courses like Ecology, Evolution, and Conservation Biology, we can increase the time spent on parasites, including adding more coverage of parasites in textbooks. We can also add new undergraduate courses and minor degrees or certificates regarding parasitology and parasite ecology to biology programs. These programs can only offer a finite number of courses, but given that parasites are ubiquitous and that some can be linked to the health of people, wildlife, and domesticated species, it should be easy to sell parasitology courses as opportunities to provide important general knowledge for many future career paths. Of course, teachers and university educators have limited time and potentially limited expertise for adding this parasite content; therefore, parasite experts can help to facilitate these changes by creating new, open-access, inclusive (i.e., not resource-intensive) lesson plans and laboratory modules for use in specialist and general courses. This content can be made interesting and relevant to students by incorporating blogs, videos, news articles, and other media into courses, and by featuring engaging topics like parasite manipulation of host behavior (see Goal 11).

Goal 10. Provide resources and training for conservation researchers regarding parasite biology, collection, identification, and preservation

Parasitism and parasitology receive only brief treatment in professional biology or conservation education programs (see Goal 11; Nichols and Gómez, 2011), and thus most conservation researchers and practitioners are likely to overlook parasite biodiversity. Even when conservation researchers and practitioners would like to incorporate parasite biodiversity into their science and management efforts, they would currently find it difficult to access the resources or expertise needed to do so. Therefore, parasitologists and parasite-relevant 
professional societies could work on building collaborations with conservationists, increasing conservationists' exposure to available resources, and creating more resources for conservationists. Together, these methods can make parasites and parasite conservation more broadly accessible and thus more widely practiced.

The most efficient way to incorporate parasites into conservation efforts will be through collaboration with parasitologists. This is currently challenging, because it can be difficult for conservation researchers and practitioners to identify collaborators with complementary expertise. Therefore, parasite-focused scientific societies (e.g. the Japanese Society of Parasitology, European Federation of Parasitologists, American Society of Parasitologists, Australian Society for Parasitology) could form conservation committees that can connect resource managers and conservation biologists with parasitological resources and expertise and communicate the value of parasite conservation. A similar model exists within other vertebrate and invertebrate societies such as the Australian Entomological Society (www.austentsoc.org.au; their Conservation Committee “...promotes research, disseminates information, develops and informs policy and manages conservation of terrestrial invertebrates...") and the American Ornithologists' Union (americanornithology.org; their Conservation Committee aims to "mobilize scientific expertise in advancing avian conservation"). With or without adding conservation committees, parasite-focused scientific societies could also support and publicize parasite conservation research by giving annual awards and grants recognizing outstanding conservation efforts or proposals, as many vertebrate-oriented societies do. This would signify to a broader scientific audience that conservation is a priority for parasitologists. Conservation- and parasitology-focused societies could even host joint meetings aimed at improving both host and parasite conservation. Ultimately, these new collaborations and interactions would benefit researchers and practitioners in both fields.

Given the taxonomist shortage (Paknia et al., 2015), parasitologists will not always be available for collaborations. However, much parasite work can be completed by people without professional parasitological training if parasitologists improve access to existing resources and create new resources. For instance, best practices for parasite collection, identification, and preservation are already published in the literature, but may not be readily accessible for a non-expert. In some cases, the best practices are not published, but rather passed through academic lineages, which leaves them similarly inaccessible to early career parasitologists and researchers in other fields who would benefit from this information. By distilling the cumulative knowledge of parasitologists into broad guidelines, parasitologists can give others a starting point from which they can build field-handling and preservation procedures fitted to their needs. This could be in the form of published guidelines in journal articles (see Clayton and Walther, 1997; Galbreath et al., 2019; Justine et al., 2012 for examples), educational videos, and workshops that provide hands-on training and tours of parasitological laboratories or natural history collections. Therefore, we re-iterate an action already suggested in Goal 1: field parasitologists, zoologists, and curators could work together to create and distribute protocols for collecting free-living species in ways that maximize collection and preservation of associated parasite data.

Goal 11. Raise awareness for parasite conservation through media and public educational venues

Academics and practitioners cannot effectively conserve parasites without the support and engagement of the public and policy makers. To improve public support for parasite conservation, we must rebrand parasite biodiversity, identify flagship parasite species that can act as ambassadors for threatened parasites, and educate people regarding the threats that parasites face and why they should be conserved (Jovani, in this special issue; also see Goal 9).

For non-parasitic invertebrates, public perceptions are largely dependent on experience and familiarity (Schlegel et al., 2015; Schlegel and Rupf, 2010), and one well-known method for familiarizing people with biodiversity is to engage them with anthropomorphized cartoons (Chan, 2012; Tam et al., 2013). This approach is already being used to some degree for parasites. For instance, there are Pokémon inspired by parasites, as well as webcomics (e.g., Inman, 2010), blogs, and t-shirt and stuffed animal collections that feature anthropomorphized parasite cartoons. Biologists could collaborate with or hire artists, social scientists, educators, and conservation practitioners to scale up these existing efforts and make the friendly faces of parasites as familiar as the ugly faces of infectious disease.

Public support could also be generated for parasites by simply improving outreach efforts that demonstrate fascinating parasite biology and ecology. For instance, Cordyceps fungi, which turn their insect hosts into "zombies", have such bizarre life cycles that they are often featured in popular media, like the video game The Last of Us (Sony Corporation, San Mateo, CA, USA). Some cordyceps are also used in traditional Chinese medicine, selling for USD $\$ 1333 / \mathrm{kg}$, and unfortunately demand is so high that this fungus is now threatened (Negi et al., 2006). Therefore, cordyceps might make a good flagship species and ambassador for parasite conservation. A range of criteria have been proposed to select the most suitable flagship species for free-living biodiversity, but many of these criteria (e.g., cultural significance, large eyes) are poorly suited to threatened parasites (Bowen-Jones and Entwistle, 2002; Home et al., 2009). Therefore, criteria specific to parasite flagship species could be developed (e.g., ease with which the species can be anthropomorphised), and that at least one flagship parasite species identified in every ecosystem that the public can associate with parasite biodiversity in that ecosystem.

Finally, institutions, researchers, and practitioners could improve public support for parasite conservation by engaging citizens in parasite education, research, and conservation. For instance, educators and researchers at museums, national parks, and science centers can collaborate to create programs about parasites and add parasites to existing programs. For example, if an institution is hosting a traveling exhibit on whales, that program could be supplemented with information about whale lice, which are so large and distinctive that they can be used to identify individual whales (Wells, 2009). To increase engagement even further, citizen science projects can be used to give citizens personal ownership over parasite research outcomes and to integrate citizens as stakeholders in conservation initiatives. For instance, the Freshwater Habitat Trust (freshwaterhabitats.org.uk) runs an ongoing citizen sciencemonitoring program for the threatened medicinal leech (Hirudo medicinalis) in Britain, which informs site identification for conservation action. As this example illustrates, citizen scientists can be mobilized to not only monitor parasites, but to actively engage the public in conservation efforts to ensure their continued survival.

\section{Closing remarks and a final goal}

The future of parasite conservation is uncertain. Support for the idea is at an all-time high in academic circles, and work on parasite conservation is just now beginning to form the basis of large collaborations, doctoral theses, and conference workshops. However, the task of actually preserving the Earth's parasite diversity remains daunting and mostly uncharted, especially as it fits into the broader picture of conservation in the Anthropocene. The accelerating challenges of climate change and other anthropogenic threats could easily overwhelm conservation efforts in the coming years; what chance do we stand to save parasites, only treated so far as gratuitous or hypothetical targets for protection?

Conservation is about more than preventing extinction: the goals we have identified here reflect the need to better understand and respond to parasite ecology in a changing world, and to advance the training and resources available to parasitologists. We hope that our proposed plan will help parasitologists and parasite ecologists to build conservation into their work in ways that are easy, low-risk, high-impact, 
cost-effective, visible to the public, and synergistic with broader wildlife conservation goals. However, making parasite conservation a reality requires a more fundamental shift, where the broader conservation community also considers parasites as important targets and is empowered to protect them. The easiest and most cost-effective way to protect parasites will usually be conserving them alongside their hosts, a paradigm shift from preserving single taxa to protecting symbiont assemblages and micro-ecosystems. But first, this requires parasites to be better understood and more visible.

In the spirit of that challenge, we propose a final ambitious goal: describe half of parasite diversity on Earth. Specifically, for each vertebrate host class and each invertebrate host order, ecologists estimate the total biodiversity in each associated parasitic clade, and then work with taxonomists to reach $50 \%$ description targets. A decade ago, this goal may have seemed impossible. Today, large host-parasite datasets, increased computing power, and new macroecological methods are being used to estimate symbiont biodiversity, and to set sampling targets (e.g., the Global Virome Project's proposed goal of describing 85\% of mammal and bird viruses; Carroll et al., 2018). These methods can be used to estimate how many host species need to be sampled to reach parasite description targets. Often, these goals are surprisingly achievable: describing half of mammal tapeworms would only require sampling roughly a thousand more mammal host species (Carlson et al., 2019a, 2019b; Strona and Fattorini, 2014). Some targets will be difficult to estimate, and initial estimates will have wide confidence intervals, especially for groups like parasites of invertebrate hosts that are underdescribed and under-represented in biodiversity data. Even so, systematically using the best-available methods to define initial $50 \%$ description targets will vastly improve our understanding of global parasite biodiversity.

Reaching $50 \%$ parasite description will create a wealth of useful information for ecology, parasitology, biomedicine, and other fields, but most importantly (for our purposes), naming millions of parasite species would be the first step towards their conservation. Frequently attributed to E.O. Wilson, one of the oldest ideas in conservation biology is that saving species requires naming them (Costello et al., 2013). Names make species easier to identify, track, and quantify, and are a basic requirement for the public-relations end of advocacy. To date, only a small percent of parasite species have been described and assigned scientific names (Carlson et al., 2019a, 2019b; Dobson et al., 2008; Larsen et al., 2017), and very few parasite species have common names, besides those that are detrimental to humans. By working towards several of the goals identified above-like digitizing collections, adding parasites to biodiversity surveys, and expanding genomic repositories- $50 \%$ of parasite biodiversity could be identified, making these species more visible and tangible to researchers, practitioners, funders, and the general public.

Fully describing $50 \%$ of parasite biodiversity, like all the other goals identified here, could be dismissed as overly ambitious and too lowpriority given the many fronts on which resources for combatting global change biology are already spread thin. Climate change, emerging diseases, and mass extinction are already monumental crises that desperately need more personnel and funding. However, we believe all available scientific evidence suggests that neglecting the hidden world of parasites only limits our efficacy in fighting these other battles, and will lead to more and worse unexpected outcomes. Parasites are the majority of food web links in many ecosystems (Dunne et al., 2013; Lafferty et al., 2008, 2006), and maybe the majority of life on Earth (Larsen et al., 2017; Windsor, 1998); small impacts on parasite diversity and community structure will ripple through host immunity and health into much broader ecosystem-level impacts-and potentially impacts on zoonotic disease (Esser et al., 2019). As some parasites emerge in new regions and others go extinct, considerable ecological turnover is likely to occur in the coming years. Without parasites in the picture, our view of the Anthropocene is dangerously limited.

In light of this looming threat, scientists urgently need a baseline understanding of parasite biodiversity, and conservationists face the task of preventing these changes as best as they can. The goal of parasite conservation is not just to protect parasitic taxa from extinction, but also to apply the lens of conservation biology to the massive changes occurring in the global host-parasite network, and to understand the threat that these changes pose to the stability of the biosphere (and our ability to live in it). Our plan captures one set of solutions among many that we hope can prepare us, as best as possible, for the uncertain future ahead.

\section{Acknowledgements}

The authors kindly thank the Ecological Society of America for supporting our workshop, as well as additional participants Kevin Burgio, Tad Dallas, and Roger Jovani; Laura Whitehouse, for her graphic design work on Fig. 1; Jonathan Wojcik for allowing the inclusion of his copyright Diplozoon illustration in Fig. 3; and dozens of collaborators and friends who have been part of the foundational work on parasite conservation, including Anna Phillips, Veronica Bueno, Carrie Cizauskas, Christopher Clements, Graeme Cumming, Eric Dougherty, Kevin Johnson, Wayne Getz, Nyeema Harris, Elizabeth Nichols, Sergey Mironov, Robert Poulin, and Heather Proctor. CJC gratefully acknowledges funding support from the Georgetown Environment Initiative, and research support from Anna Phillips and the Smithsonian National Museum of Natural History. KCB was supported by a Peter Buck Postdoctoral Fellowship from the Smithsonian National Museum of Natural History. CLW was supported by a grant from the National Science Foundation (OCE-1829509), an Alfred P. Sloan Foundation Sloan Research Fellowship, a University of Washington Innovation Award, and a University of Washington Royalty Research Fund award. Any use of trade, product, or firm names in this publication is for descriptive purposes only and does not imply endorsement by the U.S. Government.

\section{References}

Assis, J., Coelho, N.C., Alberto, F., Valero, M., Raimondi, P., Reed, D., Serrão, E.A., 2013. High and distinct range-edge genetic diversity despite local bottlenecks. PLoS One 8, e68646.

Australian Department of the Environment and Energy, 2019. https://www.environment. gov.au/cgi-bin/sprat/public/publicthreatenedlist.pl.

Bell, K.C., Matek, D., Demboski, J.R., Cook, J.A., 2015. Expanded host range of sucking lice and pinworms of western North American chipmunks. Comp. Parasitol. 82, $312-322$.

Bell, K.C., Carlson, C.J., Phillips, A.J., 2018. Parasite collections: overlooked resources for integrative research and conservation. Trends Parasitol. 34, 637-639.

Beltrame, M.O., De Porras, M.E., Barberena, R., Llano, C.L., Sardella, N.H., 2016. First study of fossil rodent middens as source of paleoparasitological evidences (northwestern Patagonia, Argentina). Parasitol. Int. 65, 352-356.

Benestan, L.M., Ferchaud, A.-L., Hohenlohe, P.A., Garner, B.A., Naylor, G.J., Baums, I.B., Schwartz, M.K., Kelley, J.L., Luikart, G., 2016. Conservation genomics of natural and managed populations: building a conceptual and practical framework. Mol. Ecol. 25, 2967-2977.

Black, G.A., 1983. Taxonomy of a swimbladder nematode, Cystidicola stigmatura (Leidy), and evidence of its decline in the Great Lakes. Can. J. Fish. Aquat. Sci. 40, 643-647.

Boast, A.P., Weyrich, L.S., Wood, J.R., Metcalf, J.L., Knight, R., Cooper, A., 2018. Coprolites reveal ecological interactions lost with the extinction of New Zealand birds. Proc. Natl. Acad. Sci. 115, 1546-1551.

Bowen-Jones, E., Entwistle, A., 2002. Identifying appropriate flagship species: the importance of culture and local contexts. Oryx 36, 189-195.

Breed, M.F., Harrison, P.A., Blyth, C., Byrne, M., Gaget, V., Gellie, N.J., Groom, S.V., Hodgson, R., Mills, J.G., Prowse, T.A., et al., 2019. The potential of genomics for restoring ecosystems and biodiversity. Nat. Rev. Genet. 1.

Bush, S.E., Reed, M., Maher, S., 2013. Impact of forest size on parasite biodiversity: implications for conservation of hosts and parasites. Biodivers. Conserv. 22, 1391-1404.

Caira, J.N., Jensen, K., 2017. Planetary Biodiversity Inventory (2008-2017): Tapeworms From Vertebrate Bowels of the Earth. Natural History Museum, University of Kansas.

Caira, J., Littlewood, D., 2013. Worms, Platyhelminthes. In: Levin, S.A. (Ed.), Encyclopedia of Biodiversity. Academic Press., San Diego, California, Waltham.

Cardoso, P., Borges, P.A.V., Triantis, K.A., Ferrández, M.A., Martín, J.L., 2012. The underrepresentation and misrepresentation of invertebrates in the IUCN red list. Biol. Conserv. 149, 147-148. https://doi.org/10.1016/j.biocon.2012.02.011.

Carlson, C.J., Phillips, A.J., 2019. Is the New England medicinal leech (Macrobdella sestertia) extinct? Biol. Conserv (in preparation).

Carlson, C.J., Burgio, K.R., Dougherty, E.R., Phillips, A.J., Bueno, V.M., Clements, C.F., 
Castaldo, G., Dallas, T.A., Cizauskas, C.A., Cumming, G.S., et al., 2017a. Parasite biodiversity faces extinction and redistribution in a changing climate. Sci. Adv. 3, e1602422.

Carlson, C.J., Muellerklein, O.C., Phillips, A.J., Burgio, K.R., Castaldo, G., Cizauskas, C.A., Cumming, G.S., Dallas, T.A., Dona, J., Harris, N., et al., 2017b. The Parasite Extinction Assessment \& Red List: an open-source, online biodiversity database for neglected symbionts. bioRxiv, 192351.

Carlson, C.J., Phillips, A.J., Dallas, T.A., Alexander, L.W., Bansal, S., 2019a. What would it take to describe global parasite diversity? bioRxiv, 815902

Carlson, C.J., Zipfel, C.M., Garnier, R., Bansal, S., 2019b. Global estimates of mammalian viral diversity accounting for host sharing. Nat. Ecol. Evol. https://doi.org/10.1038/ s41559-019-0910-6.

Carroll, D., Daszak, P., Wolfe, N.D., Gao, G.F., Morel, C.M., Morzaria, S., Pablos-Méndez, A., Tomori, O., Mazet, J.A., 2018. The global virome project. Science 359, 872-874.

Cebolla, R., Urbaneja, A., Van Baaren, J., Tena, A., 2018. Negative effect of global warming on biological control is mitigated by direct competition between sympatric parasitoids. Biol. Control 122, 60-66.

Chan, A.A.Y.-H., 2012. Anthropomorphism as a conservation tool. Biodivers. Conserv. 21, 1889-1892. https://doi.org/10.1007/s10531-012-0274-6.

Cizauskas, C.A., Carlson, C.J., Burgio, K.R., Clements, C.F., Dougherty, E.R., Harris, N.C., Phillips, A.J., 2017. Parasite vulnerability to climate change: an evidence-based functional trait approach. R. Soc. Open Sci. 4. https://doi.org/10.1098/rsos.160535.

Clayton, D.H., Walther, B.A., 1997. Collection and quantification of arthropod parasites of birds. In: Host-Parasite Evolution: General Principles and Avian Models, pp. 419-440.

Cole, K.L., Arundel, S.T., 2005. Carbon isotopes from fossil packrat pellets and elevational movements of Utah agave plants reveal the Younger Dryas cold period in Grand Canyon, Arizona. Geology 33, 713-716.

Cook, J.A., Greiman, S.E., Agosta, S.J., Anderson, R.P., Arbogast, B.S., Baker, R.J., Boeger, W., Bradley, R.D., Brooks, D.R., Cole, R., et al., 2016. Transformational principles for NEON sampling of mammalian parasites and pathogens: a response to Springer and colleagues. BioScience 66, 917-919.

Corn, J.L., Nettles, V.F., 2001. Health protocol for translocation of free-ranging elk. J. Wildl. Dis. 37, 413-426.

Costello, M.J., May, R.M., Stork, N.E., 2013. Can we name earth's species before they go extinct? Science 339, 413-416.

Cotterill, F., 1997. The second Alexandrian tragedy, and the fundamental relationship between biological collections and scientific knowledge. In: The Value and Valuation of Natural Science Collections, pp. 227-241.

Crellen, T., Allan, F., David, S., Durrant, C., Huckvale, T., Holroyd, N., Emery, A.M., Rollinson, D., Aanensen, D.M., Berriman, M., et al., 2016. Whole genome resequencing of the human parasite Schistosoma mansoni reveals population history and effects of selection. Sci. Rep. 6, 20954.

Criscione, C.D., 2016. History of microevolutionary thought in parasitology: the integration of molecular population genetics. In: A Century of Parasitology: Discoveries, Ideas and Lessons Learned by Scientists Who Published in the Journal of Parasitology. 93. pp. 1914-2014.

Criscione, C.D., Poulin, R., Blouin, M.S., 2005. Molecular ecology of parasites: elucidating ecological and microevolutionary processes. Mol. Ecol. 14, 2247-2257.

Cunningham, A.A., 1996. Disease risks of wildlife translocations. Conserv. Biol. 10, 349-353

Dallas, T., 2016. helminthR: an R interface to the London Natural History Museum's host-parasite database. Ecography 39, 391-393.

Dallas, T., Park, A.W., Drake, J.M., 2017. Predicting cryptic links in host-parasite networks. PLoS Comput. Biol. 13, e1005557.

Dallas, T.A., Aguirre, A.A., Budischak, S., Carlson, C., Ezenwa, V., Han, B., Huang, S., Stephens, P.R., 2018. Gauging support for macroecological patterns in helminth parasites. Glob. Ecol. Biogeogr. 27, 1437-1447.

DiEuliis, D., Johnson, K.R., Morse, S.S., Schindel, D.E., 2016. Opinion: specimen collec tions should have a much bigger role in infectious disease research and response. Proc. Natl. Acad. Sci. 113, 4-7.

Dobson, A., Lafferty, K.D., Kuris, A.M., Hechinger, R.F., Jetz, W., 2008. Homage to Linnaeus: how many parasites? How many hosts? Proc. Natl. Acad. Sci. 105, 11482-11489.

Doña, J., Johnson, K.P., 2019. Assessing symbiont extinction risk: insights from host symbiont coevolutionary dynamics. Biol. Conserv (in preparation).

Doña, J., Proctor, H., Mironov, S., Serrano, D., Jovani, R., 2016. Global associations between birds and vane-dwelling feather mites. Ecology 97, 3242.

Doña, J., Proctor, H., Serrano, D., Johnson, K.P., Oploo, A.O., Huguet-Tapia, J.C., Ascunce, M.S., Jovani, R., 2019. Feather mites play a role in cleaning host feathers: new insights from DNA metabarcoding and microscopy. Mol. Ecol. 28, 203-218.

Dougherty, E.R., Carlson, C.J., Bueno, V.M., Burgio, K.R., Cizauskas, C.A., Clements, C.F., Seidel, D.P., Harris, N.C., 2016. Paradigms for parasite conservation. Conserv. Biol. 30, 724-733.

Dunn, R.R., Harris, N.C., Colwell, R.K., Koh, L.P., Sodhi, N.S., 2009. The sixth mass coextinction: are most endangered species parasites and mutualists? Proc. R. Soc. Lond. B Biol. Sci. 276, 3037-3045.

Dunne, J.A., Lafferty, K.D., Dobson, A.P., Hechinger, R.F., Kuris, A.M., Martinez, N.D., McLaughlin, J.P., Mouritsen, K.N., Poulin, R., Reise, K., et al., 2013. Parasites affect food web structure primarily through increased diversity and complexity. PLoS Biol. 11, e1001579.

Durden, L.A., Keirans, J.E., 1996. Host-parasite coextinction and the plight of tick conservation. Am. Entomol. 42, 87-91.

Escobar, H., 2018. In a "foretold tragedy," fire consumes Brazil museum. Science 361, 960.

Esser, H.J., Herre, E.A., Kays, R., Liefting, Y., Jansen, P.A., 2019. Local host-tick coextinction in neotropical forest fragments. Int. J. Parasitol. 49, 225-233.
Esteban, R., Doña, J., Vierna, J., Vizcaíno, A., Serrano, D., Jovani, R., 2018. The complete mitochondrial genome of the feather mite Trouessartia rubecula Jablonska, 1968 (Astigmata: Analgoidea: Trouessartiidae). Mitochon. DNA Part B 3, 652-654.

Ewen, J.G., Armstrong, D.P., Empson, R., Jack, S., Makan, T., McInnes, K., Parker, K.A., Richardson, K., Alley, M., 2012. Parasite management in translocations: lessons from a threatened New Zealand bird. Oryx 46, 446-456.

Fairfield, E.A., Hutchings, K., Gilroy, D.L., Kingma, S.A., Burke, T., Komdeur, J., Richardson, D.S., 2016. The impact of conservation-driven translocations on blood parasite prevalence in the Seychelles warbler. Sci. Rep. 6, 29596.

Ferreira-Rodríguez, N., Akiyama, Y.B., Aksenova, O.V., Araujo, R., Barnhart, M.C., Bespalaya, Y.V., Bogan, A.E., Bolotov, I.N., Budha, P.B., Clavijo, C., et al., 2019. Research priorities for freshwater mussel conservation assessment. Biol. Conserv. 231, 77-87.

Fiorenza, E.A., Wendt, C.A., Dobkowski, K.A., King, T.L., Pappaionou, M., Rabinowitz, P., Samhouri, J.F., Wood, C.L., n.d. It's a wormy world: Meta-analysis reveals long-term change in the global abundance of parasitic anisakid nematodes in fishes and invertebrates. In preparation.

Galbreath, K.E., Hoberg, E.P., Cook, J.A., Armién, B., Bell, K.C., Campbell, M.L., Dunnum, J.L., Dursahinhan, A.T., Eckerlin, R.P., Gardner, S.L., et al., 2019. Building an integrated infrastructure for exploring biodiversity: field collections and archives of mammals and parasites. J. Mammal. 100, 382-393.

García-Varela, J.M., De León, G.P.P., 2015. Advances in the classification of acanthocephalans: Evolutionary history and evolution of the parasitism. In: Parasite Diversity and Diversification: Evolutionary Ecology Meets Phylogenetics. Cambridge University Press, pp. 182-201.

Gehman, A.-L.M., Satterfield, D.A., Keogh, C.L., McKay, A.F., Budischak, S.A., 2019. To improve ecological understanding, collect infection data. Ecosphere 10, e02770.

Gibson, D., Bray, R., Harris, E., 2005. Host-parasite Database of the Natural History Museum, London.

Gómez, A., Nichols, E., 2013. Neglected wild life: parasitic biodiversity as a conservation target. Int. J. Parasitol. Parasites Wildl. 2, 222-227.

Gompper, M.E., Williams, E.S., 1998. Parasite conservation and the black-footed ferret recovery program. Conserv. Biol. 12, 730-732.

Grayson, D.K., 2000. Mammalian responses to middle Holocene climatic change in the Great Basin of the western United States. J. Biogeogr. 27, 181-192.

Grunin, K., 1973. First discovery of larvae of the mammoth bot-fly Cobboldia (Mamontia, subgen. n.) Russanovi sp. n. (Diptera,-Gasterophilidae). Entomologicheskoe Obozrenie 52, 228-230.

Harmon, A., Littlewood, D.T.J., Wood, C.L., 2019. Parasites lost: using natural history collections to track disease change across deep time. Front. Ecol. Environ. 17, $157-166$.

Hartigan, A., Phalen, D.N., Šlapeta, J., 2010. Museum material reveals a frog parasite emergence after the invasion of the cane toad in Australia. Parasit. Vectors 3, 50.

Hellenthal, R.A., Price, R.D., 1991. Biosystematics of the chewing lice of pocket gophers. Annu. Rev. Entomol. 36, 185-203.

Hobern, D., 2019. BIOSCAN is mapping biodiversity and supporting sustainability. iBOL Barcode Bull. 9.

Home, R., Keller, C., Nagel, P., Bauer, N., Hunziker, M., 2009. Selection criteria for flagship species by conservation organizations. Environ. Conserv. 36, 139-148.

Howard, I., Davis, E., Lippert, G., Quinn, T.P., Wood, C.L., 2019. Abundance of an economically important nematode parasite increased in Puget Sound between 1930 and 2016: evidence from museum specimens confirms historical data. J. Appl. Ecol. 56, 190-200.

Hudson, P.J., Dobson, A.P., Lafferty, K.D., 2006. Is a healthy ecosystem one that is rich in parasites? Trends Ecol. Evol. 21, 381-385.

Inman, M., 2010. Why Captain Higgins is my favorite parasitic flatworm [WWW document]. URL The Oatmealhttps://theoatmeal.com/comics/captain_higgins, Accessed date: 18 August 2019.

IUCN, 2017. The IUCN Red List of Threatened Species, Version 2017-3. International Union for the Conservation of Nature, Gland, Switzerland.

IUCN/SSC, 2013. Guidelines for Reintroductions and Other Conservation Translocations. Version 1.0. IUCN Species Survival Commission Gland, Switzerland.

Johnson, P.T., Lunde, K.B., Zelmer, D.A., Werner, J.K., 2003. Limb deformities as an emerging parasitic disease in amphibians: evidence from museum specimens and resurvey data. Conserv. Biol. 17, 1724-1737.

Jørgensen, D., 2015. Conservation implications of parasite co-reintroduction. Conserv. Biol. 29, 602-604.

Jovani, R., Doña, J., del Mar Labrador, M., Serrano, D., 2017. Opening the doors of parasitology journals to other symbionts. Trends Parasitol (in press).

Justine, J.-L., Briand, M.J., Bray, R.A., 2012. A quick and simple method, usable in the field, for collecting parasites in suitable condition for both morphological and molecular studies. Parasitol. Res. 111, 341-351.

Kock, R., Woodford, M., Rossiter, P., et al., 2010. Disease risks associated with the translocation of wildlife. Rev. Sci. Tech. 29, 329.

Kuris, A.M., Hechinger, R.F., Shaw, J.C., Whitney, K.L., Aguirre-Macedo, L., Boch, C.A., Dobson, A.P., Dunham, E.J., Fredensborg, B.L., Huspeni, T.C., et al., 2008. Ecosystem energetic implications of parasite and free-living biomass in three estuaries. Nature $454,515$.

Kutz, S.J., Jenkins, E.J., Veitch, A.M., Ducrocq, J., Polley, L., Elkin, B., Lair, S., 2009. The Arctic as a model for anticipating, preventing, and mitigating climate change impacts on host-parasite interactions. Vet. Parasitol. 163, 217-228. https://doi.org/10.1016/ j.vetpar.2009.06.008.

Kutz, S.J., Ducrocq, J., Verocai, G.G., Hoar, B.M., Colwell, D.D., Beckmen, K.B., Polley, L., Elkin, B.T., Hoberg, E.P., 2012. Chapter 2 - parasites in ungulates of Arctic North America and Greenland: A view of contemporary diversity, ecology, and impact in a world under change. In: Rollinson, D., Hay, S.I. (Eds.), Advances in Parasitology, 
Advances in Parasitology. Academic Press, pp. 99-252. https://doi.org/10.1016/ B978-0-12-398457-9.00002-0.

Kwak, M.L., 2018. An expanded description of the threatened tree kangaroo tick Ixodes (Sternalixodes) dendrolagi Wilson, 1967 (Acari: Ixodidae) from Papua New Guinea. Acarologia 58, 408-413.

Kwak, M.L., 2019. Assessing and conserving threatened animal parasites: methodologies and limitations. Biol. Conserv (in preparation).

Kwak, M.L., Heath, A.C., 2018. Redescription of the kiwi tick Ixodes anatis (Acari: Ixodidae) from New Zealand, with notes on its biology. Exp. Appl. Acarol. 74, 207-223.

Kwak, M., Madden, C., Wicker, L., 2018. Ixodes heathi n. sp.(Acari: Ixodidae), a co-endangered tick from the critically endangered mountain pygmy possum (Burramys parvus), with notes on its biology and conservation. Exp. Appl. Acarol. 76, 413-419.

Lafferty, K.D., 2012. Biodiversity loss decreases parasite diversity: theory and patterns. Philos. Trans. R. Soc. B: Biol. Sci. 367, 2814-2827.

Lafferty, K.D., Kuris, A.M., 2002. Trophic strategies, animal diversity and body size. Trends Ecol. Evol. 17, 507-513. https://doi.org/10.1016/S0169-5347(02)02615-0.

Lafferty, K.D., Dobson, A.P., Kuris, A.M., 2006. Parasites dominate food web links. Proc. Natl. Acad. Sci. 103, 11211-11216.

Lafferty, K.D., Allesina, S., Arim, M., Briggs, C.J., De Leo, G., Dobson, A.P., Dunne, J.A., Johnson, P.T., Kuris, A.M., Marcogliese, D.J., et al., 2008. Parasites in food webs: the ultimate missing links. Ecol. Lett. 11, 533-546.

Larsen, B.B., Miller, E.C., Rhodes, M.K., Wiens, J.J., 2017. Inordinate fondness multiplied and redistributed: the number of species on earth and the new pie of life. Q. Rev. Biol. 92, 229-265.

Mac Kenzie, K., Pert, C., 2018. Evidence for the decline and possible extinction of a marine parasite species caused by intensive fishing. Fish. Res. 198, 63-65.

Mares, M.A., 2009. Natural science collections: America's irreplaceable resource. BioScience 59, 544-545.

Margos, G., Tsao, J.I., Castillo-Ramírez, S., Girard, Y.A., Hamer, S.A., Hoen, A.G., Lane R.S., Raper, S.L., Ogden, N.H., 2012. Two boundaries separate Borrelia burgdorferi populations in North America. Appl. Environ. Microbiol. 78, 6059-6067.

Marvier, M.A., Smith, D.L., 1997. Conservation implications of host use for rare parasitic plants. Conserv. Biol. 839-848.

Mey, E., 2002. Bird collections-an essential resource for collecting ectoparasites in particular chewing lice. Bonner Zool. Beiträge 51, 131-135.

Moir, M.L., Brennan, K.E., 2019. Incorporating coextinction in threat assessments and policy will rapidly improve the accuracy of threatened species lists. Biol. Conserv (in preparation).

Moir, M.L., Vesk, P.A., Brennan, K.E., Poulin, R., Hughes, L., Keith, D.A., McCarthy, M.A., Coates, D.J., 2012. Considering extinction of dependent species during translocation, ex situ conservation, and assisted migration of threatened hosts. Conserv. Biol. 26, 199-207.

Morand, S., 2018. Advances and challenges in barcoding of microbes, parasites, and their vectors and reservoirs. Parasitology 145, 537-542.

Negi, C.S., Koranga, P.R., Ghinga, H.S., 2006. Yar tsa Gumba (Cordyceps sinensis): a call for its sustainable exploitation. Int. J. Sustain. Dev. World Ecol. 13, 165-172. https:// doi.org/10.1080/13504500609469669.

New, T.R., 1993. Conservation Biology of Lycaenidae (Butterflies). World Conservation Union.

Nichols, E., Gómez, A., 2011. Conservation education needs more parasites. Biol. Conserv. 144, 937-941.

Northover, A.S., Godfrey, S.S., Lymbery, A.J., Morris, K., Wayne, A.F., Thompson, R.A., 2017. Evaluating the effects of ivermectin treatment on communities of gastrointestinal parasites in translocated woylies (Bettongia penicillata). Eco Health 14, 117-127.

Northover, A.S., Thompson, R.A., Lymbery, A.J., Wayne, A.F., Keatley, S., Ash, A., Elliot, A.D., Morris, K., Godfrey, S.S., 2019. Altered parasite community structure in an endangered marsupial following translocation. Int. J. Parasitol. Parasites Wildl. 10, 13-22.

Ouellet, M., Mikaelian, I., Pauli, B.D., Rodrigue, J., Green, D.M., 2005. Historical evidence of widespread chytrid infection in North American amphibian populations. Conserv. Biol. 19, 1431-1440.

Paknia, O., Sh, H.R., Koch, A., 2015. Lack of well-maintained natural history collections and taxonomists in megadiverse developing countries hampers global biodiversity exploration. Organisms Diver. Evol. 15, 619-629.

Pedersen, A.B., Jones, K.E., Nunn, C.L., Altizer, S., 2007. Infectious diseases and extinction risk in wild mammals. Conserv. Biol. 21, 1269-1279.

Pizzi, R., 2009. Veterinarians and taxonomic chauvinism: the dilemma of parasite conservation. J. Exotic Pet Med. 18, 279-282.

Plein, M., Bode, M., Moir, M.L., Vesk, P.A., 2016. Translocation strategies for multiple species depend on interspecific interaction type. Ecol. Appl. 26, 1186-1197.

Poulin, R., Morand, S., 2000. The diversity of parasites. Q. Rev. Biol. 75, 277-293.

Poulin, R., Morand, S., 2014. Parasite Biodiversity. Smithsonian Institution.

Poulin, R., Besson, A.A., Morin, M.B., Randhawa, H.S., 2016. Missing links: testing the completeness of host-parasite checklists. Parasitology 143, 114-122.

Robertson, H.A., Baird, K., Dowding, J.E., Elliott, G.P., Hitchmough, R.A., Miskelly, C.M., McArthur, N., O'Donnell, C.F.J., Sagar, P.M., Scofield, R.P., Taylor, G.A., 2017. Conservation status of New Zealand birds, 2016. New Zealand threat classification series 19. Department of Conservation, Wellington.
Rózsa, L., Vas, Z., 2015. Co-extinct and critically co-endangered species of parasitic lice, and conservation-induced extinction: should lice be reintroduced to their hosts? Oryx 49, 107-110.

Sato, T., Watanabe, K., Kanaiwa, M., Niizuma, Y., Harada, Y., Lafferty, K.D., 2011. Nematomorph parasites drive energy flow through a riparian ecosystem. Ecology 92, 201-207.

Schlegel, J., Rupf, R., 2010. Attitudes towards potential animal flagship species in nature conservation: a survey among students of different educational institutions. J. Nat. Conserv. 18, 278-290.

Schlegel, J., Breuer, G., Rupf, R., 2015. Local insects as flagship species to promote nature conservation? A survey among primary school children on their attitudes toward invertebrates. Anthrozoös 28, 229-245.

Shaw, M.R., Hochberg, M.E., 2001. The neglect of parasitic hymenoptera in insect conservation strategies: the British fauna as a prime example. J. Insect Conserv. 5, 253-263.

Speer, K.A., Luetke, E., Bush, E., Sheth, B., Gerace, A., Quicksall, Z., Miyamoto, M., Dick, C.W., Dittmar, K., Albury, N., et al., 2019. A Fly on the Cave Wall: parasite genetics reveal fine-scale dispersal patterns of bats. J. Parasitol. 105, 555-566.

Spencer, H.G., Zuk, M., 2016. For host's sake: the pluses of parasite preservation. Trends Ecol. Evol. 31, 341-343.

Springer, Y.P., Hoekman, D., Johnson, P.T., Duffy, P.A., Hufft, R.A., Barnett, D.T., Allan, B.F., Amman, B.R., Barker, C.M., Barrera, R., et al., 2016. Tick-, mosquito-, and rodent-borne parasite sampling designs for the National Ecological Observatory Network. Ecosphere 7, e01271.

Strona, G., Fattorini, S., 2014. Parasitic worms: how many really? Int. J. Parasitol. 44, 269-272.

Strona, G., Lafferty, K.D., 2016. Environmental change makes robust ecological networks fragile. Nat. Commun. 7, 12462.

Strona, G., Galli, P., Fattorini, S., 2013. Fish parasites resolve the paradox of missing coextinctions. Nat. Commun. 4, 1718.

Supple, M.A., Shapiro, B., 2018. Conservation of biodiversity in the genomics era. Genome Biol. 19, 131.

Talley, B.L., Muletz, C.R., Vredenburg, V.T., Fleischer, R.C., Lips, K.R., 2015. A century of Batrachochytrium dendrobatidis in Illinois amphibians (1888-1989). Biol. Conserv. $182,254-261$.

Tam, K.-P., Lee, S.-L., Chao, M.M., 2013. Saving Mr. Nature: anthropomorphism enhances connectedness to and protectiveness toward nature. J. Exp. Soc. Psychol. 49, 514-521. https://doi.org/10.1016/j.jesp.2013.02.001.

Thompson, R.A., Lymbery, A.J., Godfrey, S.S., 2018. Parasites at risk-insights from an endangered marsupial. Trends Parasitol. 34, 12-22.

Tingley, M.W., Beissinger, S.R., 2009. Detecting range shifts from historical species occurrences: new perspectives on old data. Trends Ecol. Evol. 24, 625-633.

USFWS, 2019. Summary of listed animals as of December 1, 2019. https://ecos.fws.gov/ ecp0/reports/ad-hoc-species-report.

Valdez, E.W., Ritzi, C.M., Whitaker, J.O., 2009. Ectoparasites of the occult bat, Myotis occultus (Chiroptera: Vespertilionidae). Western North American Naturalist 69, 364-371.

Van Oosterhout, C., Smith, A.M., Hänfling, B., Ramnarine, I.W., Mohammed, R.S., Cable, J., 2007. The guppy as a conservation model: implications of parasitism and inbreeding for reintroduction success. Conserv. Biol. 21, 1573-1583.

Van Schaik, J., Dekeukeleire, D., Kerth, G., 2015. Host and parasite life history interplay to yield divergent population genetic structures in two ectoparasites living on the same bat species. Mol. Ecol. 24, 2324-2335.

Vizcaíno, A., Doña, J., Vierna, J., Marí-Mena, N., Esteban, R., Mironov, S., Urien, C., Serrano, D., Jovani, R., 2018. Enabling large-scale feather mite studies: an Illumina DNA metabarcoding pipeline. Exp. Appl. Acarol. 76, 81-97.

Wait, L.F., Peck, S., Fox, S., Power, M.L., 2017. A review of parasites in the Tasmanian devil (Sarcophilus harrisii). Biodivers. Conserv. 26, 509-526.

Webb, R., Betancourt, J., 1990. The spatial and temporal distribution of radiocarbon ages from packrat middens. In: Betancourt, J., Van Devender, T., Martin, P. (Eds.), Packrat Middens: The Last 40,000 Years of Biotic Change. University of Arizona Press, Tuscon, AZ.

Weinstein, S.B., Kuris, A.M., 2016. Independent origins of parasitism in Animalia. Biol. Lett. 12, 20160324.

Weldon, C., Du Preez, L.H., Hyatt, A.D., Muller, R., Speare, R., 2004. Origin of the amphibian chytrid fungus. Emerg. Infect. Dis. 10, 2100.

Wells, R.S., 2009. Identification methods. In: Encyclopedia of Marine Mammals. Elsevier, pp. 593-599.

Whiteman, N.K., Parker, P.G., 2005. Using parasites to infer host population history: a new rationale for parasite conservation. In: Animal Conservation Forum. Cambridge University Press, pp. 175-181.

Windsor, D.A., 1995. Equal rights for parasites. Conserv. Biol. 9, 1-2.

Windsor, D.A., 1998. Controversies in parasitology, most of the species on earth are parasites. Int. J. Parasitol. 28, 1939-1941.

Yeates, D.K., Zwick, A., Mikheyev, A.S., 2016. Museums are biobanks: unlocking the genetic potential of the three billion specimens in the world's biological collections. Curr. Opin. Insect Sci. 18, 83-88.

Zhan, J., Ericson, L., Burdon, J.J., 2018. Climate change accelerates local disease extinction rates in a long-term wild host-pathogen association. Glob. Chang. Biol. 24, 3526-3536. 